
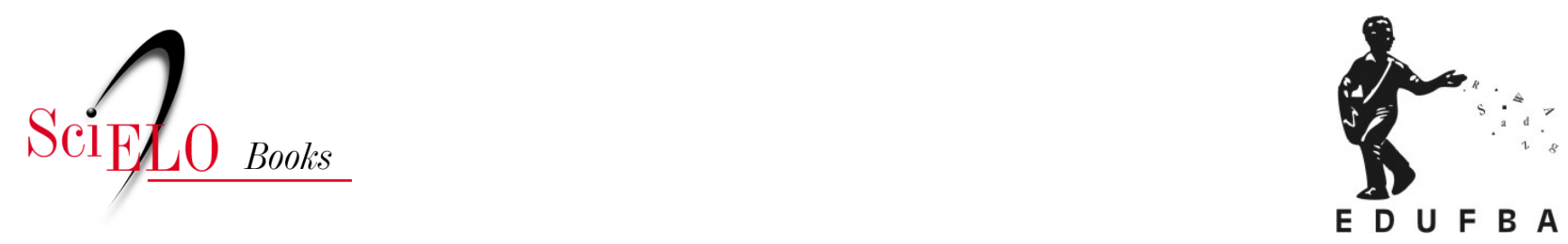

\title{
O percurso etnometodológico de uma pesquisa em Santo Amaro-BA
}

\author{
Maiza Ferreira de Andrade \\ Luiz Roberto Santos Moraes
}

\section{SciELO Books / SciELO Livros / SciELO Libros}

ANDRADE, M.F., and MORAES, L.R.S. O percurso etnometodológico de uma pesquisa em Santo Amaro-BA. In: FERNANDES, R.C.P., LIMA, M.A.G., and ARAÚJO, T.M., comps. Tópicos em saúde, ambiente e trabalho: um olhar ampliado [online]. Salvador: EDUFBA, 2014, pp. 479-502. ISBN: 97865-5630-012-2. https://doi.org/10.7476/9786556300122.0023.

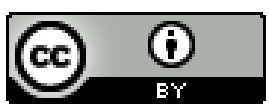

All the contents of this work, except where otherwise noted, is licensed under a Creative Commons Attribution 4.0 International license.

Todo o conteúdo deste trabalho, exceto quando houver ressalva, é publicado sob a licença Creative Commons Atribição 4.0. 


\section{O percurso etnometodológico de uma pesquisa em Santo Amaro-BA}

Maiza Ferreira de Andrade Luiz Roberto Santos Moraes

\section{Introdução}

Este capítulo apresenta o percurso metodológico da pesquisa de mestrado intitulada A contaminação por chumbo em Santo Amaro - BA: a ciência e o mundo da vida no estuário do Rio Subaé. Necessário se faz antecipar as razões pelas quais a autora adota a narrativa em primeira pessoa ao apresentar os seus resultados de campo, numa aparente transgressão das normas do texto científico. Apoiada na etnometodologia, a autora constrói um percurso fortemente marcado pelo contato com comunidades ribeirinhas do estuário do Rio Subaé, a partir da compreensão de que os objetos sociais são construídos pela interação dos sujeitos envolvidos no processo. Sua experiência de pesquisa a fez transitar entre a condição de sujeito e objeto, de pesquisadora e repórter, de observadora e observada, em um constante exercício autorreflexivo. Segundo Oliveira e Piccinini (2009), ao confrontar-se com o outro, reconhece a pesquisa como uma ação social, rica em reflexividade por possibilitar a interação da própria experiência com a do outro. O gênero de escrita adotado é predominantemente autoetnográfico, de acordo com o que recomenda Cho e Trent (2006) no que se refere à subjetividade do pesquisador como fundamento da interpretação e validação dos dados em pesquisa qualitativa. Desse modo, em um ensaio pessoal, a autora assume a sua fala, e a apresenta tal qual um dos resultados da pesquisa. 


\section{A escolha do tema}

Motivada pela possibilidade da pesquisa que articula saúde, ambiente e trabalho numa proposta multi e interdisciplinar, elegi o caso da contaminação por chumbo em Santo Amaro, para resgatar uma dívida do passado, quando fui premiada por uma reportagem sobre o descaso com o qual vinham sendo tratados os ex-trabalhadores da Companhia Brasileira de Chumbo-Cobrac. Estava diante de uma conquista da qual jamais poderia me vangloriar e que provocou mais inquietação do que alegria. Era preciso, por um dever ético, de alguma forma retribuir a Santo Amaro aquela conquista.

Fui, então, para Santo Amaro tentar compreender o significado da contaminação para pescadores e marisqueiras. A escolha desses sujeitos deu-se a partir da leitura do relatório da Avaliação de Risco à Saúde Humana por Metais Pesados em Santo Amaro da Purificação, realizada pelo Ministério da Saúde que classifica como foco secundário de contaminação por metais pesados as comunidades ribeirinhas do estuário do Rio Subaé. (BRASIL, 2003) Personagens atadas a uma dura rotina de trabalho na lama do mangue ou nos areais das coroas, as marisqueiras são consideradas como população exposta, tanto pelo contato com os sedimentos aonde se depositaram os metais pesados lançados no rio durante mais de trinta anos, quanto pelo consumo de moluscos que estariam contaminados, segundo a avaliação de risco. (BRASIL, 2003)

Conhecer esses sujeitos, e observá-los em sua jornada de trabalho, dormir sob o mesmo teto, compartilhar do alimento provido pelo estuário do Rio Subaé e ouvi-los falar de suas angústias, e da insatisfação para com a ciência e com o Estado, ofereceu material consistente para a análise aqui apresentada como um primeiro passo para a construção de um processo de comunicação de risco. A pergunta norteadora da pesquisa emergiu da lacuna deixada pela avaliação de risco do Ministério da Saúde por não realizar a comunicação de risco junto à comunidade estudada. (ANDRADE; MORAES, 2010)

Por outro lado, a constante referência dos sujeitos às pesquisas feitas sobre o caso e ao desconhecimento dos seus resultados, bem como à falta de políticas para a proteção da saúde humana e ambiental, abriram um caminho autônomo no conjunto da pesquisa. A incômoda condição de ser mais um, naquele campo visivelmente saturado de pesquisas, 
provocou a necessidade de ir além, e o que poderia ter ficado restrito a citações dos estudos mais emblemáticos feitos ao longo dos últimos 36 anos, ganhou tamanha força que requereu um levantamento exaustivo de toda a produção científica sobre a contaminação promovida pela antiga fábrica de chumbo. Desse esforço resultou uma segunda frente da revisão de literatura que inicialmente se restringia à temática do risco. Em uma busca do conjunto das pesquisas realizadas no Município, foram encontrados 64 títulos, entre teses, dissertações, monografias e artigos científicos, que, posteriormente foram doados a uma biblioteca de Santo Amaro. (ANDRADE, 2012)

As escolhas metodológicas possibilitaram lidar com tais eventos como problemas próprios do percurso da pesquisa. Deste modo, a escolha do método qualitativo se mostrou a mais adequada para a investigação proposta no projeto de dissertação que foi aprovado pelo Conselho de Ética em Pesquisa do Complexo Hospitalar Universitário Professor Edgard Santos. O primeiro contato de campo se deu por meio de incursões no estuário do Rio Subaé e nas comunidades de Caeira e São Braz com registro fotográfico, observação e notas de campo, além de entrevistas gravadas. O referencial teórico metodológico baseou-se essencialmente na análise social de riscos e na etnometodologia.

$\mathrm{O}$ processo de pesquisa se desenvolveu numa perspectiva subjetivista, sendo a dissertação apresentada em forma de ensaio autoetnográfico. A escolha desta orientação de pesquisa qualitativa resultou do intenso processo de autoavaliação da experiência vivenciada possibilitando a construção de um texto que conecta o pessoal com o cultural, sendo escrito na primeira pessoa. (OLIVEIRA; PICCININI, 2009; CHO; TRENT, 2006) Dessa forma, assume-se também com esta escolha, que, em um estudo qualitativo de abordagem interpretativa, o conhecimento depende da perspectiva da pessoa que o produz. (SANDBERG, 2005)

A opção pelo exercício do texto autoetnográfico ancorou-se, também, na possibilidade de transgressão da objetividade pretendida pelo gênero jornalístico, no qual moldei a minha expressão escrita, e do qual me afastei no período da pesquisa na pretensão de alcançar a condição "super-repórter", que o jornalista Robert Park atribuiu ao sociólogo. (COULON, 1995) 


\section{Etnometodologia}

A etapa de campo da pesquisa de mestrado que originou a dissertação A contaminação por chumbo em Santo Amaro-BA: a ciência e o mundo da vida no estuário do Rio Subaé, foi orientada pela etnometodologia, tendo como principal referência à obra de Alain Coulon (1995). (ANDRADE, 2012) Trata-se de uma corrente da sociologia americana que surge nos anos 1960 tendo como obra fundadora Studies in Etnomethodology, de Harold Garfinkel e efetua uma ruptura radical com os modos de pensamento da sociologia tradicional. "Mais que uma teoria constituída, ela é uma perspectiva de pesquisa, uma nova postura intelectual" que amplia o pensamento sociológico, dando mais importância à compreensão do que a explicação. (COULON, 1995, p.7)

Compreender o mundo social da população ribeirinha do estuário do Rio Subaé era um dos propósitos da pesquisa, na tentativa de encontrar respostas para questões como: por que marisqueiras e pescadores mantinham sua rotina no Rio, indiferentes ao risco da contaminação por metais pesados?; Havia meios de identificar as áreas que foram classificadas como foco de contaminação no Rio Subaé?; Isso faria alguma diferença?; Como eles lidavam com o risco avaliado pela ciência?; Eles aceitavam o risco estabelecido pela ciência?; e Seria esta uma questão de aceitar os riscos, ou de se estar involuntariamente submetido a uma situação que lhe fora imposta?

Encontrei em Coulon (1995) a base teórica que precisava para ir ao campo, mesmo convivendo com a dualidade da minha condição de pesquisadora/repórter, que marcou a fase inicial da pesquisa. No embate entre jornalismo x pesquisa social, dois aspectos importantes foram trazidos para situar cada um desses campos. (COULON, 1995) O primeiro aspecto, segundo Coulon (1995), é que a sociologia teria negligenciado a importância dos aportes teóricos e metodológicos do interacionismo simbólico e tratado esta corrente de pensamento com desprezo "como uma empreitada de tipo jornalístico, sem um verdadeiro estatuto científico". (COULON, 1995, p.15) Estava evidente aí a condição de subciência atribuída então ao jornalismo, atividade pela qual fui inserida na problemática de Santo Amaro.

O segundo aspecto veio com o destaque do papel do jornalista estadunidense Robert Park para os pilares da etnometodologia. (COULON, 
1995) Robert Park, um dos fundadores da Escola de Chicago, estudou sociologia na Universidade de Heidelberg, na Alemanha e começou a ensinar sociologia aos 49 anos, mas sem negar o seu passado de jornalista. Para Park, o sociólogo era uma espécie de super-repórter, "que informa de maneira um pouco mais precisa e com um pouco mais de distância que a média”. (PARK, 1921 apud COULON, 1995, p.15) As pesquisas sociológicas para Robert Park, em suas técnicas e conteúdo não seriam mais do que formas superiores de jornalismo: "a ciência é simplesmente mais persistente em sua curiosidade, um pouco mais exigente e exata em suas observações do que o senso comum". (PARK, 1921 apud COULON, 1995, p.15)

A compreensão de que objetos sociais são construídos embasou o percurso da pesquisa a partir do fenômeno empírico de observação do mundo da vida das marisqueiras nas comunidades pesqueiras do Rio Subaé. Concordando com a definição de que a etnometodologia seja uma via para a tentativa de compreensão do que os indivíduos veem, descrevem e propõem em conjunto para uma dada situação, a questão de como os pescadores e marisqueiras se colocam ante o risco de contaminação, iluminou-se diante deste e de outros conceitos. (COULON, 1995)

Foi, dessa forma, mobilizada pela etnometodologia, que parti para o campo da pesquisa, para fazer contato com o dia a dia das pessoas que vivem da cata de mariscos no estuário do Rio Subaé. Começava a vislumbrar o objeto da pesquisa, ciente de que a compreensão dos fenômenos sociais só é possível no contexto em que eles se inserem. (LAPERRIÈRE, 2008) O contato com o campo transcorreu no período de nove meses, de fevereiro a novembro de 2011, quando se deram os encontros com os sujeitos nas ruas, em eventos públicos, em suas casas e em seu trabalho e, especialmente, no manguezal do estuário.

\section{Ensaio pessoal}

Definida a perspectiva subjetivista como primeira das decisões metodológicas tomadas, a próxima veio a ser quanto à linguagem a ser utilizada. Os dados foram se delineando a partir da fala das pessoas, em conversas informais e em entrevistas gravadas, das anotações no diário de campo, e da observação, partindo sempre do princípio fundamental 
de que os fatos sociais são construções práticas das interações dos sujeitos, sejam observadores ou observados. A experiência pessoal de campo embasou a interpretação dos dados encontrados, a partir do equilíbrio de uma escuta crítica e empática. (LAPERRIÈRE, 2008)

A opção por ensaio pessoal de cunho autoetnográfico surgiu em decorrência de todo o processo, fortemente marcado pelo impacto da interação da pesquisadora com os sujeitos que foram tomando seu lugar na narrativa e contribuindo para o alcance do objetivo geral da pesquisa, o de refletir sobre a contaminação por chumbo em Santo Amaro a partir das pesquisas realizadas sobre o tema e do ponto de vista de marisqueiras e pescadores.

O percurso entre a mesa de trabalho do pesquisador e o campo é permeado pelas condições da pesquisa, pela postura do pesquisador e até mesmo os problemas encontrados são parte integrante da pesquisa, como destaca Coulon (1995). A dificuldade que tive em ir para o campo, a resistência em deixar a mesa e ir para o mangue para compartilhar o dia a dia nas comunidades pesqueiras foi um dos problemas enfrentados.

A pesquisa é por si só uma ação social, rica em reflexividade. (OLIVEIRA; PICCININI, 2009) Tal conceito, também caro à etnometodologia, mostra que as práticas reflexivas são aquelas nas quais refletimos sobre o que fazemos ao confrontar a nossa experiência com a do outro. A experiência da pesquisa foi um exercício constante de reflexividade desde o momento no qual reconheci o sentimento de saturação por pesquisas e uma latente demanda por participação na construção do conhecimento em torno da contaminação, demonstrados pelos sujeitos. Seria essa pesquisa mais uma a somar-se a tantas outras já realizadas em Santo Amaro e sobre as quais o senso comum é de que não tiveram retorno para a comunidade? Como enfrentar esse desafio, explicitamente verbalizado na fala do pescador ao queixar-se das pesquisas anteriores: "Me sinto enganado por pesquisadores. Trouxeram o que de reparação para a comunidade ao dizer que o mangue está contaminado?”. (PESCADOR - JOSÉ ROQUE DE JESUS FILHO, 2011) Estava diante do fato social que seria determinante para a compreensão que buscava. Uma decisão decorrente dessa constatação foi a de ampliar a revisão bibliográfica, até então restrita à temática do risco, para abarcar a produção científica sobre o caso da contaminação por chumbo em 
Santo Amaro. Era preciso conhecer mais a fundo o que fora pesquisado, na tentativa de encontrar alguma resposta possível para o porquê da saturação da comunidade por pesquisas.

Se, por um lado, a revisão da literatura sobre a contaminação por chumbo em Santo Amaro possibilitou o acesso ao conhecimento construído pela ciência, por outro, me convocou a olhar o campo a partir da perspectiva de pescadores e marisqueiras, o que se fez possível quando participei de uma jornada de trabalho com as marisqueiras da Caeira, dentro do manguezal. Essa experiência vivida é o ponto de partida do conhecimento que foi possível construir a cerca da realidade de homens e mulheres que têm suas vidas atadas ao ciclo da maré que banha o estuário do Rio Subaé. É, também, reveladora da raiz fenomenológica dessa empreitada de pesquisa, de abordagem interpretativa, porque calcada na relação inseparável entre o sujeito e o mundo no qual atua, seja na condição de pesquisadora ou de pesquisada. (SANDBERG, 2005)

São sujeitos deste estudo três professoras de São Braz, cinco marisqueiras aposentadas de São Braz, quatro marisqueiras ativas de Caeira, um pescador aposentado de São Braz, um pescador ativo de Caeira, e um agente de saúde de São Braz. Os encontros aconteceram no período de fevereiro de 2011 a fevereiro de 2012 com registros de campo, reunidos em entrevistas gravadas, observação participante, captação de imagens e, principalmente, anotações em diário de campo.

\section{Resultados de campo}

\section{Um dia no mangue}

Numa manhã de tempo aberto e maré tardeira ${ }^{1}$ juntei-me ao grupo de marisqueiras liderado por Rosália. Quando cheguei ao local, o grupo já estava embarcado em duas canoas, e Rosália deu pressa. Como tinha sido prevenida das peças que deveria trajar, e as estava usando por baixo da roupa, só fiz tirar as peças de cima e acrescentar a touca que Rosália me emprestou. Ela também forneceu o sapatão, um tipo de calçado improvisado para proteger os pés na andada pela lama. Era feito com pedaços da perna da calça jeans, costurado em uma das extremidades,

1 Maré cheia começando mais tarde 
permitindo que fosse calçado como uma meia e com tiras de plástico presas ao tecido para serem amarradas na canela. Ouvi a recomendação para amarrar fortemente as tiras para que o sapatão não saísse do pé. Uma das marisqueiras, irmã de Rosália, relatou que, após longas jornadas de trabalho, fica com os pés inchados, o que a faz pensar que seja devido à amarração das tiras.

Embarquei em uma das canoas e fui apresentada ao grupo de cinco mulheres e um homem. Pouco tempo depois, as remadas cessaram e Rosália falou que as outras mulheres queriam que lhes fosse explicado o motivo da minha presença ali. Disse de onde vinha, minha afiliação institucional e do propósito de conhecer o trabalho das marisqueiras para uma pesquisa sobre as condições de saúde, do ambiente e do trabalho no Rio Subaé. Eram explicações um tanto vagas, mas optei por não detalhar muito, até porque, assim como Cicourel (apud COULON, 1995), antes da ida ao campo, também não sabia muito bem o que estava procurando. Propositadamente não explicitei o interesse pela questão da contaminação para que a mesma emergisse da fala delas. De novo, como Cicourel (apud COULON, 1995), receei que a apresentação do tema pudesse influenciar no comportamento delas.

Apesar do grupo contar com a presença de um homem, que também iria mariscar naquele dia, optei por usar o termo marisqueiras para me referir ao grupo, concordando com a ideia de que o uso da denominação no feminino resulta do reconhecimento da centralidade do papel da mulher nesse tipo de trabalho.

A questão do gênero é marcante na divisão do trabalho de extração de mariscos, realizada principalmente por mulheres e crianças. O trabalho de homens na extração do marisco ocorre quando estes não dispõem de recursos para adquirir canoas para participar da pesca, ou em situações de invalidez parcial ou ainda quando idosos. (PENA; FREITAS; CARDIM, 2011, p.3385)

Descemos o Rio Subaé até o trecho do manguezal, conhecido como Tarioba, próximo à cidade de São Francisco do Conde. Rosália explicaria depois, que elas preferem locais mais distantes de Santo Amaro porque têm mais mariscos do que mais perto da cidade. Na viagem, o clima de total camaradagem é marcado pelo riso constante, compartilhado entre todas e provocado pela sucessão de casos do dia a dia da comunidade ou de fatos da vida delas, sempre narrados com muito humor. "Aqui, a gente trabalha e brinca muito, não é pra você estranhar, nem 
tomar nota de tudo que a gente fala". (MARISQUEIRA - MARIA ROSÁLIA DA CRUZ DE JESUS, 2011) Essa ressalva era, principalmente, por causa do conteúdo sexual das brincadeiras. Entre elas, ri-se de tudo e de todos, ri-se da própria condição que as submete àquele tipo de rotina de trabalho árduo que as cobre de lama, que maltrata o corpo, que as adoece, mas que as diverte e as proporciona o ganho, mesmo não sendo no justo valor do esforço que empreendem na tarefa de extrair o marisco do manguezal. Essa situação também é descrita por Pena, Freitas e Cardim (2011, p. 3385), ao destacarem que devido à "insuficiência de produção e sem condições de conservação e armazenagem, a mariscadeira necessita vender o produto imediatamente por preços abaixo do valor de mercado".

Desembarcamos na Tarioba cerca de 40 minutos depois de deixarmos o porto da Caeira. As canoas foram atadas nos troncos da vegetação do mangue, bem como sacolas com objetos que não seriam usados na faina. Calçada, com o sapatão, dei os primeiros passos dentro da lama como uma criança que está aprendendo a andar, e segui Rosália. Estava diante da realidade da vida cotidiana das mulheres que sobrevivem da extração de mariscos no mangue. "A realidade por excelência", que segundo Luckmann e Berger (1999, p.38), “está aí, e não requer verificação”. Nos primeiros instantes, tive sensação de nojo, e certo desespero pela falta de chão firme sob os pés. Os passos eram vacilantes pelo temor de afundar nos buracos dos caranguejos. Fui prontamente orientada a pisar nos afloramentos das raízes das árvores em lugar das partes mais limpas, onde podiam estar os buracos. Rosália riu ao ver os meus primeiros passos e quis saber o que eu pretendia fazer. Disse que a acompanharia, observando o seu trabalho, que ela ficasse à vontade em sua rotina e que contasse com a minha ajuda se fosse preciso. Não demorou para que Rosália começasse a me passar as 'camas' de sururu para eu ir debulhando. É que para se fixarem no solo lamacento, os mariscos enredam-se em fibras que os prendem a porções de lama, chamadas de camas e onde se reproduzem. Assim, aos poucos fui entendo a lógica daquele trabalho ambulante:

O trabalho das mariscadeiras no arenoso da praia e no manguezal é de natureza ambulante onde mantém a flexão dorsal por longo tempo. Deambulam e cavam com movimentos dos membros superiores em ritmo acelerado, quase sempre em flexão dorsal, se deslocam por pedras e pelo arenoso da 
praia, sob sol intenso e com os olhos fixos no arenoso para identificar mariscos. São ambientes sempre úmidos e completamente diferentes, quando se consideram as características do manguezal. (PENA; FREITAS; CARDIM, 2011, p. 3387)

Aos poucos, o grupo começa a se dispersar, com cada uma tomando o seu rumo dentro do manguezal, em busca da 'mina', lugar com muita concentração de sururus. Escondidos sob a lama, só podem ser encontrados por olhos treinados a distingui-los em meio a galhos caídos, tocos, raízes do mangue, tudo numa coloração cinza que pouco a pouco vai se tornando a mesma das roupas usadas pelas mulheres. É quando "mimetizam-se" como se refere Josué de Castro às populações extrativistas dos manguezais do Nordeste (PENA; FREITAS CARDIM, 2011). A primeira das seis horas passadas dentro do mangue foi a mais longa de todas, pela sensação de desconforto, por me achar em um ambiente à primeira vista tão inóspito e do qual não seria possível sair a qualquer momento. Estava totalmente entregue a decisões alheias a minha vontade e o melhor a fazer seria submeter-me às condições dadas. Passada esta fase, aos poucos fui entendendo a razão pela qual elas, apesar de dependerem de um trabalho tão difícil para ganhar a vida, pareciam contentes, simplesmente. Isso era notado pela calma com que se deslocavam, pela movimentação incessante, pela ausência de lamentação, irritação, estresse, ou qualquer outra manifestação de contrariedade. Estavam ali por inteiro, apesar de admitirem que fariam outra coisa, caso tivessem escolha. Que preferiam tudo aquilo ao trabalho de empregada doméstica pelo qual já haviam passado.

Em todo o estuário, não há qualquer referência aos resultados da análise da água, sedimentos e dos moluscos coletados em 16 pontos de amostragem quando da realização da avaliação de risco do Ministério da Saúde, há 8 anos. Elas não se referem à contaminação, mas usam estratégias como a de ir para locais mais distantes da Cidade, onde teria maior ocorrência dos mariscos e a de lavarem as mãos e os pés com cloro quando saem do manguezal. Para elas, a lama do mangue não é suja. "Esse cheiro, é dele mesmo". (MARISQUEIRA - MARIA ROSÁLIA DA CRUZ DE JESUS, 2011) Aceitei a explicação e segui a jornada, lembrando-me das reflexões de Beck sobre a indiferença aos riscos: 
A indiferença diante dos riscos, de todo modo imperceptíveis, que sempre encontra na superação da carência palpável sua justificação (Terceiro Mundo) é o terreno cultural e político no qual os riscos e ameaças florescem, crescem e frutificam. (BECK, 2010, p. 54)

As conversas iam se tornando esparsas, devido à distância que tomavam uma das outras e, nesse instante, o silêncio do mangue chegava a causar certo torpor, dando projeção ao canto de pássaros e até mesmo ao sutil estalar das cascas dos sururus. ${ }^{2}$ Assim, passaram-se seis horas, sem que as tivesse visto parar para lanchar ou beber água. De acordo com Pena, Freitas e Cardim (2011), a falta de pausa no trabalho revela a pressão social para intensificar as atividades a fim de coletar a maior quantidade possível de mariscos. Àquela altura já tinha dado uma boa ajuda a Rosália arrancando os sururus das camas, o que causou divertidos comentários das outras, afinal ela era a única que contava com uma "assistente".

Quando percebem que se aproxima a hora do retorno, antes que a maré comece a encher, o ritmo é acelerado. Pouco a pouco, as que se distanciaram procuram retornar para perto das companheiras, tendo Rosália como referência. Ela exerce uma liderança natural, mas o que prevalece é o senso de colaboração mútua, apesar de a produção ser individual. Pude observar o cuidado de uma delas em prestar ajuda à colega que, por causa do peso da carga de sururu que levava na cabeça, afundava uma das pernas até a altura da coxa ao pisar nos buracos de caranguejo. Foram quedas sucessivas, que a obrigava a arriar a carga na lama, e com muita dificuldade, levantar-se do buraco, e com a ajuda da colega, recolocá-la sobre a cabeça. Ao retornarem ao local onde haviam deixado à canoa, cuidavam de lavar os mariscos para tirar o excesso de lama e catavam galhos secos para serem usados nos fogareiros que fariam em suas casas para fermentá-los. Com muito cuidado adentravam na maré para tirar a lama das roupas e começavam a fazer comentários sobre a jornada. Com o grupo todo reunido, embarcavam e seguiam rio acima, animadas para alcançarem a coroa ainda em tempo de poder tomar banho em local mais seguro e, finalmente, merendar.

2 Essa observação de campo contradiz a fala da marisqueira Mara, da Ilha de Maré, segundo a qual, o sururu do mangue, porque fica embaixo da lama, não estala. (PENA; FREITAS; CARDIM, 2011, p.3388) 
Dali, retornariam para casa, dando sequência à jornada que só terminaria após o cozimento, descasca, pesagem, ensacamento e armazenamento do produto sob refrigeração. Na volta, as canoas foram unidas com corda e em uma delas foi levantada um pequena vela conhecida por traquete, que, empurrada pelo vento, dispensava o grupo do esforço de remar contra a corrente. No retorno, as conversas já não são tão animadas quanto na ida para o trabalho. Com o deslocamento mais lento das canoas, percebe-se que o cansaço vai dando lugar ao silêncio e à inevitável contemplação da paisagem estuarina, confirmando a tese de Pena, Freitas e Cardim, (2011, p. 3386) que:

[...] objeto de trabalho da mariscadeira não é apenas uma coleta de mariscos existentes na natureza, mas um universo de representações subjetivas compreensíveis nas esferas sócio antropológicas, essencial para a construção de sua identidade $[\ldots]$

\section{A vida de Lívia}

Conheci Lívia na minha primeira visita ao estuário do Rio Subaé, na comunidade de São Braz. Era uma tarde do mês de novembro de 2010 e Lívia tinha acabado de chegar da maré, e a fiz interromper a lida. Após a coleta, ela ainda tinha que ferventar e catar o marisco, separando o material comestível da casca. Em outros tempos, naquele horário ela estaria à numa sala de aula, exercendo o magistério. Cheguei até ela por indicação de um agente comunitário de saúde que, por sua vez, fora indicado por um informante de Santo Amaro. A prática do método bola de neve para a construção da rede de relacionamentos na comunidade permeou todo o trabalho de campo, o que facilitou os encontros e enriqueceu o universo de sujeitos envolvidos.

Desempregada, para sobreviver, naquele ano vivia de alguma renda aferida com aulas de reforço escolar, cata de siri, e lavagem de roupa, além da ajuda do marido. Era novembro, aproximava-se o final de um ano em que esteve fora da escola, depois de dez dedicados ao ensino, por razões segundo ela, de ordem política.

Se você for de casa em casa e perguntar quem é a melhor professora de São Braz, vão dizer: é Lívia, e, no entanto, fiquei um ano desempregada. É tanta barbaridade, que dá vontade de renunciar ao magistério. Não se pode misturar política com educação. (PROFESSORA - LIVIA OLIVEIRA, 2010) 
A compreensão clara da incompatibilidade dessas duas dimensões e a falta de modéstia ao se autoavaliar dispensava explicações. Compreendi isso ao ver a reverência com que todos, jovens e velhos a tratam na comunidade. A sua pequena estatura não lhe impede de se impor como gigante em defesa da educação, e da decência da condição humana mesmo enfrentando tantas adversidades. Naquela tarde, ainda em trajes da maré, com a blusa enlameada, recebeu-me com certa desconfiança, mas me deixou ver o quanto tinha e precisava falar, com sua voz firme e seu português limpo e bem pronunciado. No seu casebre, a poucos metros do porto, vivia com dois dos três filhos e o companheiro, pescador.

A lida principal da família era no Rio Subaé. Lívia tanto pescava de rede, quanto mariscava. Entusiasta da associação local de pescadores e mariscadeiras, lamentava o pouco interesse dos associados, que não contribuíam, apesar de a entidade estar "toda legalizada”. Quando retornei meses depois, a encontrei acometida de catapora, febril e visivelmente debilitada. Foi um reencontro rápido, somente para marcar a próxima vinda, em momento mais apropriado.

\section{Contaminação}

Lívia não reconhece que haja contaminação por metais pesados nas áreas de pesca de São Braz - que é um braço do Rio Subaé conhecido como "canal" de São Braz. Ela acusa a contaminação por esgotos domésticos.

Todo o esgoto de São Braz vai para a maré. Tanto que, o estudo de impacto ambiental (do Ecoresort Cajaíba) não achou poluente pesado, só fezes. Mas, lá perto de Santo Amaro não. A professora que estudava os mariscos daqui, levando a lama e os mariscos para examinar, nunca encontrou nada nos mariscos de São Braz. (PROFESSORA - LIVIA OLIVEIRA, 2010)

Lívia expressa o que é do senso comum em São Braz quando o assunto é a contaminação por metais pesados. A contaminação química não é ali. Os dejetos domésticos são drenados para a maré e não parecem incomodar. "Fortalece os caranguejos e siris", é o que diz o pai de Lívia.

Desde a década de 1970, as águas e sedimentos do rio têm sido examinados, mesmo que de forma esporádica. A carga de metais pesados lançados diretamente no rio, que foi responsável por teores de 
chumbo até 60 vezes superiores aos limites estabelecidos pela Organização Mundial de Saúde, segundo Reis (1975), cessou em 1993 com o fechamento da fábrica, mas ainda preocupa. A literatura mais recente sobre o caso da contaminação do Rio Subaé por metais pesados difere da opinião de Lívia ao afirmar que a contaminação afetou e ainda afeta toda a extensão do estuário do rio, de Santo Amaro até a sua foz na Baía de Todos os Santos. A avaliação de risco à saúde humana por metais pesados em Santo Amaro realizada pelo Ministério da Saúde em 2003, traz em suas conclusões:

Os dados levantados neste estudo, bem como os dados de estudos anteriores, quando avaliados pelos valores de referência ("níveis limites de efeito" TELs $=$ Threshold effects) utilizados pela USEPA (1996) indicam a contaminação dos sedimentos do Rio Subaé, a partir de Santo Amaro da Purificação e até sua foz na Baía de Todos os Santos, com os contaminantes chumbo, cádmio, cobre, mercúrio, níquel e zinco. Estes sedimentos contaminados representam uma rota potencial de exposição para as populações que consomem a biota proveniente destes ambientes aquáticos. (BRASIL, 2003, p. 250)

O relatório do MS é desconhecido na comunidade de São Braz, assim como em toda Santo Amaro. Os seus resultados não foram discutidos com a população identificada como exposta nos dois focos da contaminação definidos no estudo, a área em torno da PLUMBUM (antiga Cobrac) e no Rio Subaé. Embora ateste a contaminação, o relatório também afirma que não é possível prever a mobilização e o deslocamento dos metais contidos nos sedimentos do rio coletados nas proximidades da PLUMBUM para áreas de maior desenvolvimento biótico, como nos manguezais, utilizado para atividades de captura de moluscos, importante segmento concentrador de metais pesados na biota marinha comestível. Decorridos 10 anos do término das atividades da fábrica, os contaminantes ainda se concentram nas proximidades do ponto de emissão. (BRASIL, 2003)

$\mathrm{Na}$ exposição das recomendações de saúde para os dois grupos da população exposta - a população moradora em torno da PLUMBUM (500m) e a população consumidora de moluscos, em especial as famílias de pescadores da colônia de Caieiras $(\text { sic })^{3}$ - o relatório da avaliação de risco afirma que o molusco (sururu) está contaminado com chumbo e cádmio:

3 Diferentemente do relatório do MS, em Santo Amaro a grafia desta palavra é Caeira. 
Conforme pode ser observado no capítulo V - Seleção dos Contaminantes de Interesse -, os moluscos contaminados são todos originários de uma única coroa (borda da praia do rio onde nascem os sururus), aquela situada mais próxima à colônia e identificada como coroa de caieiras. Os moluscos originários das outras 16 coroas pesquisadas não estão contaminados. (BRASIL, 2003, p.247)

Mais adiante, o relatório reafirma: "os moluscos das outras coroas não estão contaminados, porém como os sedimentos do rio Subaé estão contaminados, é necessário realizar um monitoramento periódico". Neste sentido, a compreensão de Lívia de alguma forma está articulada com as conclusões do relatório, que especifica como contaminados os sururus da coroa da Caeira, embora reconheça a necessidade de monitorização do estuário como um todo.

Depois de percorrer o Rio Subaé, do porto da Caeira até a foz, e da convivência com pescadores e marisqueiras foi possível distinguir o ambiente da coroa, do ambiente do manguezal e saber que o molusco sururu ocorre com mais predominância no mangue e não nas coroas. Nessas áreas, marisca-se o mapé, e um dos locais onde são mais procurados é na coroa de Brotas, situada à jusante da foz do Rio Pitinga, um dos afluentes do Rio Subaé, e onde são lançados os resíduos da fábrica de papel Penha (antiga Impasa), ainda em atividade em Santo Amaro. A morte total do manguezal do Rio Pitinga nos anos 1980 é fato conhecido de todos os ribeirinhos e tema de um documentário feito por pesquisadores estrangeiros que ainda são lembrados em São Braz. Assim, a discussão da avaliação de risco com a comunidade precisa acontecer e esclarecer a que mariscos estão se referindo, se mapé, se sururu.

A avaliação de risco do MS calculou as doses de exposição ao chumbo e ao cádmio na alimentação em Santo Amaro, para duas faixas etárias, até 11 anos e peso corporal médio de 30kg, e 12 anos e mais, com peso médio de $70 \mathrm{~kg}$. Os cálculos foram baseados em estudos com animais, sendo a extrapolação para humanos considerada envolta em muitas incertezas, como admite o relatório. Os cálculos foram feitos tomando por referência a frequência de uma refeição à base de moluscos por semana, e com uma estimativa de consumo de $50 \mathrm{~g}$ de mariscos para crianças e $100 \mathrm{~g}$ para adultos. O estudo concluiu que, nessas condições, para a população em geral, em especial a da colônia de pescadores de Caeira, as doses de exposição para chumbo e cádmio estão abaixo do 
PTWI (ingesta semanal provisória tolerável) definido pela Organização Mundial de Saúde (OMS). Para as crianças que ingerem moluscos, no entanto, a dose de exposição encontrada se iguala ao nível de risco mínimo para o cádmio. O relatório adverte, no entanto, que, diante das incertezas da relação do chumbo e cádmio com o câncer, e admitindo que ambos sejam carcinogênicos, há risco de desenvolver câncer para toda dose diferente de zero. (BRASIL, 2003)

Nas cozinhas das comunidades de Caeira e São Braz, assim como deve ser também em Santo Amaro e nas inúmeras cozinhas aonde chegam os sururus do Rio Subaé, o risco do consumo que consta no relatório do MS não faz parte das preocupações dos consumidores. Em Caeira e em São Braz os mariscos estão presentes na alimentação cotidiana e, preparados como muqueca, servidos com molho de pimenta, são irresistíveis ao paladar, inclusive das crianças, como foi possível observar na casa de Lívia. Em Caeira, a muqueca de mapé também é iguaria ricamente preparada com os ingredientes e modo de fazer tradicionais há muitas gerações. O que o relatório também sinaliza nas recomendações para a saúde, e que até então não se configurou em Santo Amaro, é a necessidade de se:

[...] estabelecer um programa de educação ambiental e comunicação de risco para a população a fim de que ela possa apropriar-se de conhecimentos para melhor conduzir-se, com autonomia, para a proteção e promoção de sua saúde. (BRASIL, 2003, p. 249)

A contaminação não preocupa tanto Lívia quanto a falta de uma escola de segundo grau na comunidade. "A prefeitura dá o transporte para os jovens irem estudar o segundo grau lá (em Santo Amaro). Só aqui que não tem escola de segundo grau”. Ela acha que é porque nunca teve alguém para representar politicamente a localidade. "O que tentava ser, morreu do coração”. Segundo Lívia, ele tocava pandeiro no samba chula, grupo que ficou famoso após a conquista de um importante prêmio cultural. O cantor do grupo, e compositor de 500 sambas, é gari e analfabeto e quando não está viajando com o grupo, em turnês nacionais e internacionais, pode ser visto em serviço na limpeza das ruas de São Braz, ou tocando o seu pequeno rebanho bovino, no final da tarde, como pude observar. 


\section{Crianças}

São Braz fica a $6 \mathrm{~km}$ de Santo Amaro. O meio de transporte mais utilizado são as vans que partem da Ponte do Moringa, no centro de Santo Amaro. Fomos de van à aula presencial do curso de Pedagogia à distância que Lívia frequenta, em Santo Amaro, com a ajuda de uma bolsa de estudos do governo federal. É visível a sua satisfação em estar na faculdade. Na turma, ela se destaca pela leitura fluente dos textos e pela atenção durante a aula, o que não é comum a toda a turma, de 29 mulheres e apenas um homem.

Quando a professora tutora falou da necessidade de o professor perceber em que nível está cada um dos alunos, mediante o diagnóstico do seu grau de alfabetização (se domina a escrita, leitura e interpretação), Lívia comentou sobre um aluno que, estando na $4^{\mathrm{a}}$ série ainda não estava alfabetizado, e que ela não conseguiu evitar que ele repetisse o ano. Sua colega, de São Braz, também relatou caso semelhante. “Tem muitos casos assim lá (em São Braz)”, disse Lívia. Tais observações me fizeram lembrar dos estudos que foram feitos com crianças de Santo Amaro quanto aos níveis de chumbo no sangue.

É sabido que o chumbo está associado à deficiência de cognição em crianças. Pensei se o fato relatado por elas não estaria relacionado a isso. Evitei falar disso com elas, pois, na condição de observadora não seria recomendável entrar no tema/objeto da observação sem que o mesmo surgisse espontaneamente. Pensei também de como tem sido negligenciada a necessidade de estudos mais aprofundados na população exposta à contaminação em Santo Amaro. Os estudos epidemiológicos até então realizados foram do tipo transversal e revelaram a situação em momentos pontuais, como em 1980, 1985 e em 1992, não tendo sido feitos de forma continuada como os de coorte, que permitiriam um acompanhamento mais aprofundado.

A impressão que dá, ouvindo os depoimentos e observando como a pesquisa se desenvolveu em Santo Amaro é que o caso da contaminação se tornou atraente e ainda atrai porque fornece evidências, garante resultados rápidos, estatisticamente significantes e publicáveis, e condizentes com os estudos de corte transversal. Até então ninguém se interessou em realizar um estudo longitudinal (coorte), que talvez garantisse maior acesso da população estudada aos resultados e ao 
conhecimento das suas reais condições de saúde, enquanto expostos a fatores de riscos da contaminação por metais pesados, como a ingestão de peixes e mariscos do Rio Subaé, e pelo contato com a escória de chumbo, sobretudo entre as crianças.

De acordo com Guerra (2010), a coleta esporádica de sangue de alguns indivíduos de uma população dificilmente refletirá o grau de exposição da população, especialmente se essas coletas não forem feitas de forma sistemática, baseadas em desenhos epidemiológicos adequados e com intervalos bem definidos. Ela cita o exemplo dos EUA:

[...] pela grande pressão da sociedade civil e pela notória contaminação dos ambientes urbanos de algumas cidades americanas, há atualmente nos EUA um programa nacional para detecção de crianças contaminadas por chumbo. Nesse programa, o sangue é utilizado como marcador de contaminação e as coletas são realizadas anualmente em todas as crianças do país, sendo todas as amostras analisadas em um único Centro. (GUERRA, 2010, p. 7)

Em sua avaliação, Guerra (2010, p.13) afirma que a ausência de achados clínicos na população de Santo Amaro estudada "pode refletir a ausência de investigação específica do desenvolvimento psicomotor das crianças envolvidas" e que, "em nenhum dos estudos analisados foi relatada a realização de avaliação do desenvolvimento psicomotor das crianças afetadas, sejam os realizados pela Universidade Federal da Bahia, sejam nos relatórios de acompanhamento realizado pela PLUMBUM por determinação judicial”. (GUERRA, 2010, p.13)

A preocupação com as crianças frente ao risco da contaminação por chumbo e a falta de retorno das pesquisas realizadas com esse segmento da população são recorrentes nos relatos como pôde ser observado na entrevista de grupo realizada em São Braz, da qual participaram três professoras, um agente comunitário de saúde e um pescador.

Professora 1: Esse povo que fez a coleta nas escolas não era nem de Santo Amaro. Era de São Paulo, era de não sei aonde.

ACS: Justamente isso...

Professora 1: É um problema sério. Precisa vir gente de outro estado pra descobrir alguma coisa, pra fazer um estudo, levantamento de pessoas afetadas, enquanto a própria prefeitura, o Poder Público podia tomar uma posição.

Vocês conhecem os levantamentos que foram feitos?

Professora 1: Não 
ACS: Hum... só por alto assim. É justamente o que estou dizendo, a gente ficou excluso. A gente só sabe das coisas através da Avicca.

Professora 2: A única coisa que eu sei também sobre isso é que detectou algum problema nas crianças, no colégio, na escola.

Aqui?

Professora 2: Sim. Ficou as crianças indo tomar medicação na escola. Então, tomou aquela medicação, e depois ninguém veio dar o retorno. Tomou a medicação e acabou. Não levou pra avaliar as crianças novamente.

Não ouviu dizer se teve algum efeito ou não?

Professora 2: Foi só pra dizer que tava dando a medicação...

Pescador: Até minha neta teve problema também.

Quando foi isso?

Professora 2: Muitas crianças iam pro colégio tomar essa medicação. Até dia de sábado, quando tava marcado pra tomar a medicação, mesmo que não tivesse aula, todas as crianças tinham que ir pro colégio. Acho que foi em 2004.

Durante quanto tempo?

Professora 2: Acho que mais de um mês. E veio já assim, as doses certinhas de cada um, mas aí o diretor chamou os pais na escola

Os pais receberam os exames?

Professora 2: Não. Eu acho que não. Até onde eu sei é que chegou a relação das crianças que teriam que tomar aquela medicação e os professores tinham que tá sempre chamando, mandando recado pros pais pra mandar no horário pra tomar a medicação.

Alguém aqui teve algum filho ou parente nesta situação?

ACS: Tive um vizinho. Acho que Rodrigo teve, não foi Rodrigo?

Os pais da sua neta receberam o exame?

Pescador: Que nada...

ACS: Foi uma coisa superficial...

Professora 2: Foi só mesmo pra distribuir aquela medicação, como se as crianças fossem uma cobaia.

ACS: E nem todos os lugares foram contemplados com isso, né?

Professora 2: nem nós professores sabiam porque, realmente, aquela criança tava tomando aquilo e quando ia encerrar esse tratamento, quer dizer, tratamento tem um prazo. Todo mundo tinha o mesmo diagnóstico. Tomou. Acabou a dose de uma, acabou da outra e da outra. Não levou novamente pra fazer outra avaliação pra ver se realmente a medicação tinha feito efeito.

E quem era o responsável pela... 


\section{Professora 2: Medicação?}

Pela medicação?

Professora 2: Quando chegou na escola, o diretor do colégio ficou responsável pela medicação.

Sim, mas, quem trazia a medicação?

Professora 2: Não sei quem trazia não.

Professora 1: Eu lembro que foi um grupo de pessoas de outro estado que estavam fazendo um trabalho. Não era nem daqui da Bahia.

\section{Samba}

Lívia cria versos de cordel e é entusiasta do samba chula. O grupo se reúne esporadicamente em um bar do povoado. Naquele domingo tive a sorte de assistir a uma apresentação para uma equipe de filmagem. Com todo o instrumental, o grupo encanta pela riqueza do ritmo e autenticidade dos seus integrantes. As letras são do compositor João do Boi, homem de mais de 60 anos, farrista e galante. Em total sintonia com o parceiro Alumínio, a todo instante puxa os sambas, mesmo quando os músicos fazem pausa, e pontua os versos com brados como: "no samba, sou eu e Alumínio. Quando a gente se for, acabou o samba de São Braz". E mais: "Se eu fosse um homem que soubesse assinar o meu nome, ninguém ia poder comigo". Logo o pequeno espaço do bar encheu-se da alegria do samba. Homens, mulheres e crianças estavam todos integrados ao canto e à dança. Há muita força e poder em gestos tão simples. O requebro não é privilégio das moças. Na roda de samba, manda a elegância, que não escolhe idade, mas que se encorpa mais soberana nas mulheres maduras. Vi Lívia bater palmas, balançar o corpo, mas não entrou na roda. Um pescador que havia encontrado na maré, naquela manhã, perguntou pelas fotos que eu estava fazendo (o observador sendo observado). Ele falou da minha semelhança com "Charlotte", a pesquisadora norte-americana que estudou a contaminação do manguezal na década de 1980, segundo os relatos que ouvi repetidas vezes.

Seis meses depois, encontrei Lívia novamente exercendo o magistério, no colégio de São Braz, graças à intervenção de um vereador de Santo Amaro, o que a fez contar com a renda de um salário mínimo. 
Neste caso, a política se aliou à educação, e, felizmente, por uma boa causa.

\section{Considerações finais}

A ausência das ciências humanas nas pesquisas sobre a contaminação em Santo Amaro acompanhou uma tendência global observada desde a década de 1980 pelos críticos do modelo de avaliação de risco, sendo recente o interesse desse campo do conhecimento, notadamente da comunicação. (SHORT JR., 1984) A manifesta saturação da população local por mais pesquisas é um sinal de que os interesses dos afetados não têm sido considerados, tanto pela falta de acesso aos resultados dos inúmeros estudos já realizados, quanto pela inação dos setores públicos responsáveis pela adoção de medidas recomendadas pelos pesquisadores. (DI GIULIO, 2010) Tudo quanto podia ter sido quantificado pelos peritos já o foi. Como aproximar esses dois mundos, o da ciência e o mundo da vida dos sujeitos das pesquisas senão pela comunicação, em um processo construído com a participação de todas as vozes legítimas?

O interesse por Santo Amaro como campo de pesquisa é crescente, se observada a evolução das pesquisas ao longo dos últimos 36 anos, desde que a contaminação por chumbo e cádmio apresentou suas primeiras evidências, tanto nas águas do Rio Subaé, quanto na urina dos trabalhadores da antiga fábrica.

O caso de Santo Amaro volta e meia chega às mais altas tribunas, do Senado e da Câmara dos Deputados, impulsionado pelo desejo latente de justiça para com os ex-trabalhadores, e com todas as outras vítimas da contaminação, incluindo aí o estuário do Rio Subaé. O desafio é pensar no que fazer com o passivo ambiental. Soluções como o reprocessamento das cerca de 500 mil toneladas de escória de chumbo a base de ácido clorídrico separaram os campos da engenharia e da saúde em um embate de racionalidades dado o potencial de risco da operação. (ANDRADE, 2012) Sem a participação qualificada da comunidade de Santo Amaro nessa discussão, corre-se o risco de o valor de mercado do chumbo remanescente na escória ser o balizador das decisões a serem tomadas. 
A crítica consolidada pelas ciências sociais aos modelos quantitativistas, por meio da análise social de riscos, tem significativa contribuição a dar. Do mesmo modo, metodologias apoiadas na participação das comunidades afetadas apontam um novo e promissor caminho para a pesquisa. A epidemiologia popular vem estabelecer o protagonismo dos leigos na pesquisa, desde a coleta e interpretação de dados juntamente como os peritos em um processo que leva à compreensão das ameaças existentes e a busca por soluções no campo das políticas públicas de saúde. (BROWN, 1992)

Uma das abordagens da epidemiologia popular, a pesquisa baseada na participação da comunidade - Community based participatory research - CBPR - revela-se adequada para o caso das comunidades afetadas pela contaminação química, não somente no estuário do Rio Subaé, mas na Baía de Todos os Santos, devido ao passivo ambiental da indústria petroquímica. (LEUNG; YEN; MINKLER, 2004) De acordo com esses autores, apesar dos avanços da epidemiologia moderna, este campo permanece limitado em sua capacidade para explicar por que certos resultados ocorrem e para gerar o tipo de resultados que podem ser traduzidos em programas ou políticas para melhorar a saúde.

A criação de parcerias com a comunidade, de tal forma que representantes da comunidade possam participar na definição do problema de pesquisa, na interpretação dos dados, e aplicação das descobertas, pode ajudar a responder a estas preocupações. (LEUNG; YEN; MINKLER, 2004, p. 499)

A demanda por participação na tomada de decisão envolvendo riscos é uma tendência global e desafia a busca por novas metodologias para além do que estabelece as agências norte-americanas, que tem sido referência no País. A fala de um pescador do Rio Subaé ao revelar sua decepção para com os pesquisadores decorre da esperança frustrada por conhecimento sobre o ambiente no qual trabalha e do qual sobrevive e também por alternativas à sentença condenatória dos sururus por um crime que eles não cometeram.

A rotina de marisqueiras e pescadores no estuário do Rio Subaé em nada se alterou ao longo de todos esses anos em que o Rio recebeu toneladas de metais pesados, e outras contribuições de efluentes industriais e domésticos desde a sua nascente, em Feira de Santana, a 55km da foz, na Baía de Todos os Santos. Se não parou a coleta, também não 
cessou o consumo desses produtos, especialmente do sururu, que teve o seu consumo desaconselhado pelo Ministério da Saúde (2003) após a realização da Avaliação de Risco à Saúde Humana por Metais Pesados em Santo Amaro.

Para pescadores e marisqueiras, o tema causa desconforto uma vez que a referência à contaminação é uma ameaça a sua atividade de subsistência. O desconforto também é proveniente da falta de informações precisas sobre a situação da contaminação no estuário. "Sim, está contaminado, mas onde, em que parte do Rio tem metais pesados, onde é que tem marisco contaminado, quanto tem de contaminação?" são questões que um pescador levanta, desafiando o conhecimento técnico. Assim, como o da maioria das pesquisas realizadas em Santo Amaro, o relatório da avaliação de risco à saúde humana empreendida pelo Ministério da Saúde, em 2003, repousa numa estante. Não somente porque o relatório não esteja acessível à população interessada, mas também por não ter envolvido a comunidade e pelo fato de as suas recomendações ainda não terem sido implementadas, a avaliação de risco ainda não parece ter cumprido o seu papel.

\section{Referências}

ANDRADE, M. F. de. A contaminação por chumbo em Santo Amaro-BA: a ciência e o mundo da vida no estuário do Rio Subaé. 2012. 106f. Dissertação (Mestrado em Saúde, Ambiente e Trabalho), Universidade Federal da Bahia, Salvador, 2012.

ANDRADE, M. F.; MORAES, L. R. S. A abordagem da comunicação em estudos de avaliação de risco: uma análise crítica do caso de Santo Amaro. In: SIMPÓSIO BRASILEIRO DE SAÚDE AMBIENTAL, I. , 2010, Belém. Anais. . Rio de Janeiro: Abrasco, 2010. p 69.

BECK, U. Sociedade de Risco: rumo a uma outra modernidade. 1. ed. São Paulo: Editora 34, 210. 368p.

BRASIL. Ministério da Saúde. Avaliação de Risco à Saúde Humana por Metais Pesados em Santo Amaro da Purificação. Brasília, 2003.

BROWN, P. Popular Epidemiology and Toxic Waste contamination: lay and professional ways of knowing. Journal of Health and Social Behavior, n. 33, p. 267-281, 1992. 
CHO, J.; TRENT, A. Validity in qualitative research revisited.

Qualitative Research. London. England, v. 6, n. 3, p. 319-40, 2006.

COULON, A. Etnometodologia. Petrópolis: Ed. Vozes, 1995. 134p.

DI GIULIO, G. M. Comunicação e governança do risco: exemplos de comunidades expostas à contaminação por chumbo no Brasil e Uruguai. 2010. 327f. Tese (Doutorado em Ambiente e Sociedade), Universidade Estadual de Campinas, São Paulo, 2010.

GUERRA, C. S. Utilização de dentes decíduos de regiões com diferentes históricos de contaminação ambiental para detecção de grupos de crianças expostas ao chumbo no Brasil. 2010. 175f. Tese (Doutorado em Biologia Buco-Dental), Universidade Estadual de Campinas, Campinas, São Paulo, 2010.

LAPERRIÈRE, A. Os critérios de cientificidade dos métodos qualitativos. In: POUPART, Jean et al. A pesquisa qualitativa: enfoques epistemológicos e metodológicos. Petropólis: Ed. Vozes, 2008. 464p. (Coleção Sociologia)

LEUNG, M. W.; YEN, I; MINKLER, M. Community-based participatory research: a promising approach for increasing epidemiology's relevance in the 21st century. International Journal of Epidemiology, n. 33 p. 499-506, 2004

LUCKMANN, T.; BERGER, P. L. A construção social da realidade: tratado de sociologia do conhecimento. Petropólis/RJ: Ed. Vozes, 1999.

OLIVEIRA, S. R.; PICCININI, V. C. Validade e reflexividade na pesquisa qualitativa. Cadernos EbapeBR, Rio de Janeiro, v. 7, n. 1, p. 89-98, 2009.

PENA, P. G. L.; FREITAS, M. C. S.; CARDIM, A. Trabalho artesanal, cadências infernais e lesões por esforços repetitivos; estudo de caso em uma comunidade de mariscadeiras na Ilha de Maré, Bahia. Ciência \& Saúde Coletiva, v. 16, n. 8, p. 3383-3392, 2011.

REIS, J. O. N. Determinação polarográfica de $\mathrm{Pb} 2+$ e Cd2+ em águas do rio Subaé - Sto. Amaro - Bahia. 81f. Tese (apresentada para concurso de Professor Assistente do Departamento de Química Geral e Inorgânica) Instituto de Química. Universidade Federal da Bahia, Salvador, 1975.

SANDBERG, J. How do we justify knowledge produced within interpretative approaches? Organizational Research Methods, v. 8. n. 1, p. 41-68, 2005. SHORT JR. , J. F. The social fabric at risk: toward the social transformation of risk analysis. American Sociological Review, v. 49, p. 711-725, 1984. 